\title{
Develop Model for Controlled Depth Milling by Abrasive Water Jet of Ti6Al4V at Jet Inclination Angle
}

\author{
Van-Hung Bui, Patrick Gilles ${ }^{(凶)}$, Guillaume Cohen, and Walter Rubio \\ Institut Clément Ader (ICA), CNRS-INSA-ISAE-Mines Albi-UPS, Université de Toulouse, \\ 3 rue Caroline Aigle, 31400 Toulouse, France \\ patrick.gilles@insa-toulouse.fr
}

\begin{abstract}
Abrasive water jet machining (AWJM) is an interesting solution for the production of shallow pockets in metal sheets made of titanium alloys. Indeed, it produces low cutting forces and heat generation and prevents deformation of these parts after machining. In addition, it has the advantage of only using two raw materials: sand and water. It is possible to generate pocket edges with an imposed geometry using AWJM, but it is necessary to tilt the axis of the jet. The material removal mechanism is then a function of the inclination angle. The presented study propose an improved model for modelling the pocket profile in TiAl6V parts. The experimental results shows that the model is efficient as the precision is around $5 \%$.
\end{abstract}

Keywords: Abrasive water jet machining (AWJM) - Titanium alloy $\cdot$ Alloy cutting depth model

\section{Introduction}

Titanium alloys, and the most used one Ti6Al4V, presents several advantages compared to other metallic materials, such as lightweight, excellent fatigue performance and high resistance to the aggressive environment. These advantages are the reasons of its wide employability material in industry, especially in aerospace. However, its machinability is affected by other properties as high strength, low thermal conductivity and chemical reactivity with cutting tool materials, so it is challenging to choose conventional machining processes in this case. Particularly, pylon components in the aeronautical structure have thin and large shape. Choosing conventional milling process for those parts causes dramatically reduction of the tool life due to galling tendency and deformation of parts due to heat generation caused by high cutting forces. All these restrictions led to the rapid development of machining titanium alloys by non-conventional process like laser, chemical and electrical discharge and abrasive water jet machining (AWJM). Among non-conventional machining methods, AWJM is a promising technique with outstanding characteristics in comparison with conventional machining. AWJ uses a simple tooling (pure water and abrasive particles), it imposes minimum forces on the workpiece and it

(C) The Author(s) 2021

L. Roucoules et al. (Eds.): JCM 2020, LNME, pp. 21-27, 2021.

https://doi.org/10.1007/978-3-030-70566-4_5 
does not produce any heat-affected zone. Also in the aspect of impact on the environment, it could be considered to be the least harmful.

Due to these advantages, AWJ process has been applied for machining with controlled depth of metals [1-3]. Some reports [4-6] has shown that the desired 3D complex geometry milled by AWJ process can be achieved by governing different slopes which are equal to the local slope of that desired 3D geometry, obtained by changing the angle between the jet axis and the target surface.

However, many studies have shown that there is a wide kind of process parameters in the AWJ process [7-9]. It makes difficult to control the amount of the material removal volume. A small variation in the characteristic of the jet plume causes a fluctuation of eroded material mass along the trajectory of the jet plume. This raises a significant issue for controlled-depth milling in AWJ machining. For those reasons, controlling the jet footprint geometry plays the most important role in generating desirable surface geometries. Thus, a predictive geometrical surface profile model is very importance to fulfil these challenges and improve the advantages of abrasive water jet technology.

The present work develops an efficient and simple geometrical milling model, taking into account the inclination jet angle $(\alpha)$ (Fig. 1-a). As shown by the study presented in [10], only the inclination angle variation is relevant to be considered. Impingement angle (Fig. 1-b) and 5-axis combination are intent to be studied in further work. It makes an effort to insight the kerf generation process with respect to a key kinematic process parameter $(\alpha)$ as a basis to develop strategies for machining controllable pocket shape and further for complex geometries in abrasive water jet technology.
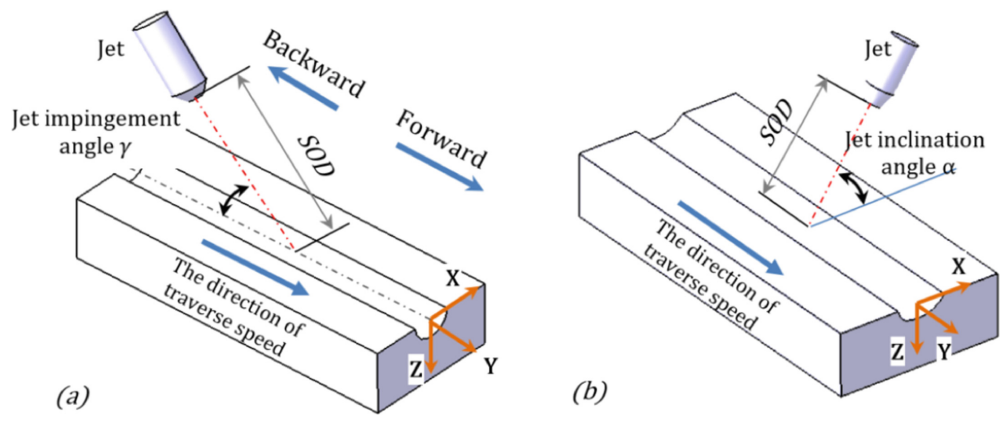

Fig. 1. Definition of jet angle

To enable this, several works are conducted as follows:

- (i) Introduction of an extended model [10] of the profile for the pocket machined taking into account the inclination angles of the jet $(\alpha)$.

- (ii) Experimentations with different inclination angles of the jet.

\section{Proposed Model with the Inclination Angle of the Jet}

The energy distribution in the AWJ is identified experimentally as a Gaussian distribution $[9,11]$, which means that at any cross-section of the jet plume (perpendicular to the jet 
axis), the velocity profile of water follows nearly Gaussian distribution [12]. Moving of the jet plume over a workpiece surface generates an elementary pass with bell shape as a result of Gaussian distribution. The model of the kerf profile of the elementary pass and pocket milled by abrasive water jet process have been introduced [10, 13]. Thus an open pocket can be generated by using several successive elementary passes with a suitable distance (Pitch) (Fig. 2).

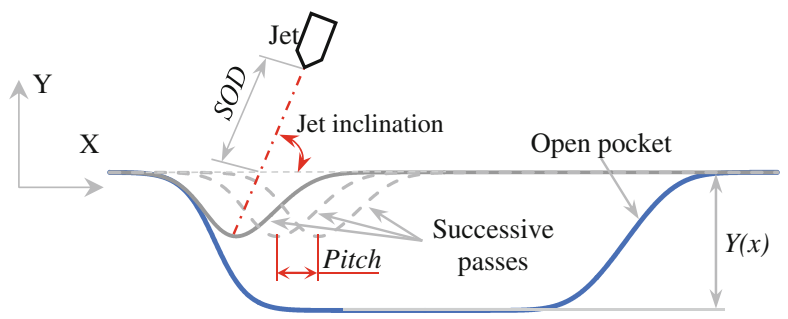

Fig. 2. Schematic of open pocket profile generated by successive elementary passes corresponding to the jet inclination angle at $\alpha$

In addition, in order to narrow the influence of complex operating parameters, a given configuration of the machine is defined by dividing into two categories: $(i)$ the setting parameters and (ii) controlled parameters. The setting parameters are not easily modifiable during milling including: pressure $(P)$, grade of abrasive particle, abrasive flow rate $(\mathrm{ma})$, and standoff distance $(S O D)$. The controlled parameters are defined as the ones that could be modified during machining by the NC program. Considering an elementary pass, in this present study, the only controlled parameter is the traverse speed $(V f)$.

The modelling of kerf profile of elementary pass, taking into account the influence of the jet inclination angle (Fig. 2), has been developed in the previous works [10]. The present model (Eq. 1) is developed further to predict the open pocket on abrasive water jet milling and it works with the open pocket generated at different focusing tube inclined angles corresponding to a specific machine configuration:

$$
Y(x)=\sum_{i=0}^{n}\left[H(\alpha) \cdot K e(\alpha) \cdot H(V f) \cdot e^{-\left(\frac{x-i \cdot p i t c h \cdot \sin (\alpha)}{B(V f)}\right)^{2}}\right]+\cot (\alpha) \cdot x
$$

where $K e(\alpha)$ is the erosion factor which depends on the jet inclination angle and it allows the governing the equation to be more suitable. $K e(\alpha)$ is identified analytically to find the specific erosion rate on the target material. $H_{e}(\alpha)$ factor consider the effect of a succession of elementary passes depending on the real inclination angle of the jet. The maximum depth $H(V f)$ and the width factor $B(V f)$ of the corresponding elementary pass generated at the jet inclination angle of $90^{\circ}$, these factors have been introduced in $[10,13]$ and defined using Eq. 2 and Eq. 3.

$$
\begin{gathered}
H(V f)=H o \times V f^{H v} \\
B(V f)=B o \times B f^{B v}
\end{gathered}
$$

$H o, H v, B o$, and $B v$ are coefficients that are determined experimentally. 


\section{Experiment}

The experiments for model validation are conducted on a five-axis AWJ machining system (FLOW MACH4C). All input parameters are selected as it was done in previous works $[10,13]$ which play the role of the setting parameters in a given machine configuration. In addition, the results from previous works [10, 13, 14] has demonstrated the efficiency of the model to predict the geometrical characteristics of the kerf profile of both the elementary pass and pocket for various values of traverse speed. The present work only consider the influence of the jet inclination angle $(\alpha)$ on the milling process. The tests were implemented using a specific value of the traverse speed, $V f=$ $1000 \mathrm{~mm} / \mathrm{min}$, with different jet inclination angles.

In order to demonstrate the efficiency of the model (Eq. 1), the effect of the jet inclination angles in pocket generation is performed (Fig. 3-a by varying the angle $\alpha$ in the range of $50^{\circ}-90^{\circ}$ with two pitch values $(0.7 \mathrm{~mm}$ and $1.1 \mathrm{~mm})$.

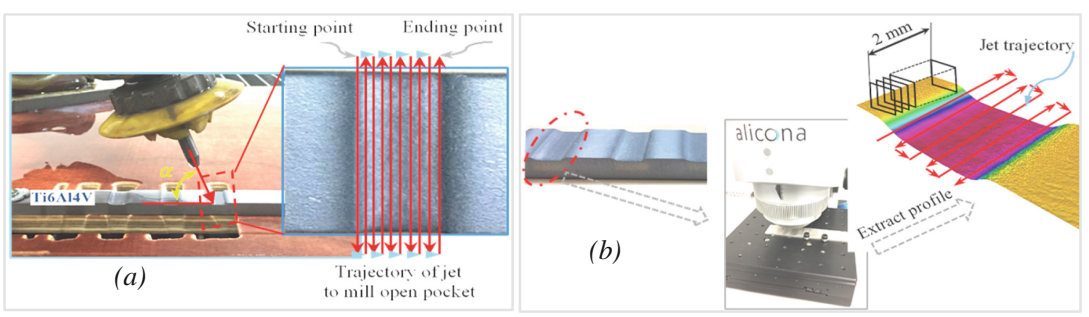

Fig. 3. Experimental setup and measurement employed for machining open pocket by AWJ

The identification of the dimensional characteristics of the pocket are extracted from the outcome of measuring on an ALICONA IF optical profilometer (Fig. 3-b). This apparatus is able to measure 1000 curves, distributed regularly over $2 \mathrm{~mm}$, using.

\section{Result}

Based on the experimental result of milling elementary passes with three levels of the traverse speed (Vf) presented in Eq. 2 and Eq. 3 [10, 13], the coefficients $H o=336.074$, $H v=-1.000, B o=1.224, B v=-0.066$ were determined. Besides, the erosion factor $\mathrm{Ke}(\alpha)$ was determined by the experiments and given in [10]. It should be noted that once the erosion coefficient $H_{e}(\alpha)$ is taken into account in the model (Eq. 1), there is a good agreement between the model predictions and the measured profiles with a mean error which is computed by Eq. 4 .

$$
\text { Error }=\frac{\text { Depth }_{\text {Modeled }}-\text { Depth }_{\text {Measured }}}{\text { Depth }}
$$

The mean errors (Table 1) are always negative values and all the absolute values are smaller than 5\%; the maximum mean value is observed at the inclination angles of $70^{\circ}$ and also $80^{\circ}$ for both two cases of the pitch. 
Table. 1. Modeled and measured depth.

\begin{tabular}{l|l|l|l|l|l|l}
\hline$\alpha$ & \multicolumn{3}{l|}{ Pitch =0.7 mm } & \multicolumn{2}{l}{ Pitch =1.1 mm } \\
\cline { 2 - 7 } & $\begin{array}{l}\text { Experiment } \\
(\mathrm{mm})\end{array}$ & Model $(\mathrm{mm})$ & Error $(\%)$ & $\begin{array}{l}\text { Experiment } \\
(\mathrm{mm})\end{array}$ & Model (mm) & Error (\%) \\
\hline $90^{\circ}$ & 0.868 & 0.844 & $-1.63 \%$ & 0.497 & 0.488 & $-1.84 \%$ \\
\hline $80^{\circ}$ & 0.789 & 0.772 & $-2.04 \%$ & 0.485 & 0.466 & $-4.09 \%$ \\
\hline $70^{\circ}$ & 0.752 & 0.740 & $-1.56 \%$ & 0.466 & 0.459 & $-3.35 \%$ \\
\hline $60^{\circ}$ & 0.709 & 0.706 & $-0.36 \%$ & 0.470 & 0.453 & $-2.43 \%$ \\
\hline $50^{\circ}$ & 0.719 & 0.710 & $-1.23 \%$ & 0.496 & 0.483 & $-2.57 \%$ \\
\hline
\end{tabular}
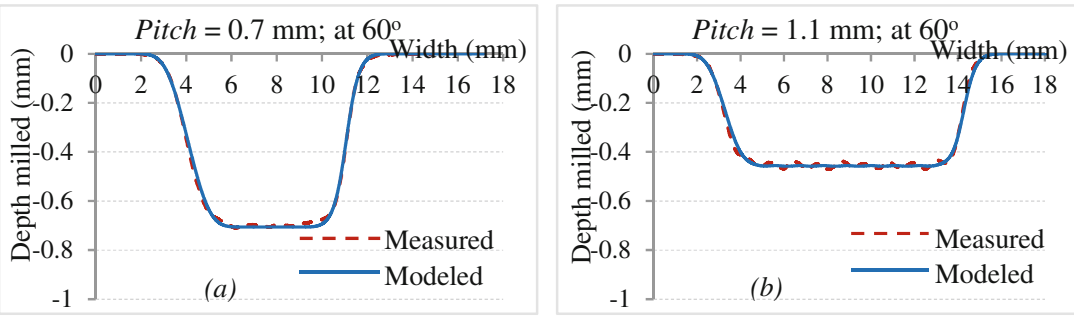

Fig. 4. A comparison measured and modelled profiles corresponding to the jet inclination angle at $\alpha=60^{\circ} ;(a)$ - Pitch $=0.7 \mathrm{~mm}$ and $(b)$ - Pitch $=1.1 \mathrm{~mm}$.

Furthermore, Fig. 4 indicates a good fitting of measured profile with modelled profile at $60^{\circ}$ of the jet inclination angle for the pitch $=0.7(\mathrm{~mm})$ and $1.1(\mathrm{~mm})$.

Figure 5 shows the value of $H_{e}(\alpha)$ factor which defined by experiment at a given jet inclination angle for two values of the pitch steps. In both cases, the $H_{e}(\alpha)$ factor is a function of the jet inclination angle and dependence of $H_{e}(\alpha)$ fully matches with the linear trendline (dot lines is the best-fit line).
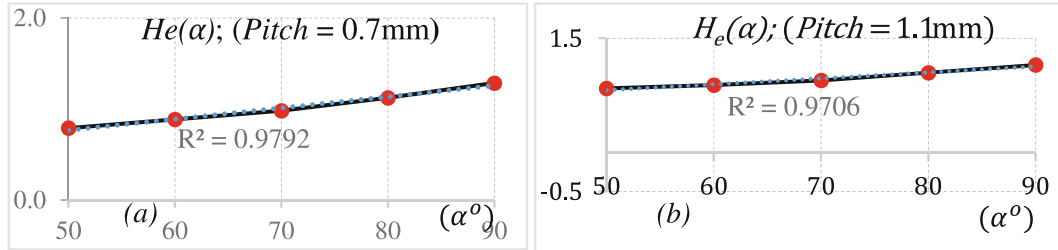

Fig. 5. $H_{e}(\alpha)$ factor defined experimentally as a function of jet inclination angle. The dot line represents the best fit line: $a)$ Pitch $=0.7(\mathrm{~mm}) ; b)$ Pitch $=1.1(\mathrm{~mm})$. 


\section{Conclusion}

In this work, the generation of milled pocket at various jet inclination angles is investigated by considering the model for $2 \mathrm{D}$ cross-section profile milling by AWJ applications. The model has been assessed by milling open pockets in titanium alloy (Ti6Al4V). The process is controlled by the traverse speed $(V f)$ and the jet inclination angles $(\alpha)$, other process parameters are chosen to establish a given machine configuration. The machined pocket profile is analysed to get control for the depth of the pocket by varying a jet inclination angles from $50^{\circ}$ to $90^{\circ}$. The geometry of the profile of the open milled pocket significantly depends on the jet inclination angle $(\alpha)$. The mean error is less than $5 \%$.

\section{References}

1. Paul, S., Hoogstrate, A.M., Van Luttervelt, C.A., Kals, H.J.J.: An experimental investigation of rectangular pocket milling with abrasive water jet. J. Mater. Process. Technol. 73, 179-188 (1998)

2. Chakraverti, G., Kanthababu, M., Goutham, U., Hasu, B.S.: Experimental Investigation of Pocket Milling on Inconel 825 using Abrasive Water Jet Machining. FME Trans. 44(2), 133-138 (2016)

3. Fowler, G., Shipway, P.H., Pashby, I.R.: Abrasive water-jet controlled depth milling of Ti6Al4V alloy - an investigation of the role of jet-workpiece traverse speed and abrasive grit size on the characteristics of the milled material. J. Mater. Process. Technol. 161(3), 407-414 (2005)

4. Srinivasu, D.S., Axinte, D.: An analytical model for top width of jet footprint in abrasive waterjet milling: A case study on SiC ceramicsg. Proc. Inst. Mech. Eng. Part B J. Eng. Manuf. 225(3), 319-335 (2011)

5. Tamannaee, N., Spelt, J.K., Papini, M.: Abrasive slurry jet micro-machining of edges, planar areas and transitional slopes in a talc-filled co-polymer. Precis. Eng. 43, 52-62 (2016)

6. Billingham, J., Miron, C.B., Axinte, D.A., Kong, M.C.: Mathematical modelling of abrasive waterjet footprints for arbitrarily moving jets: part II - overlapped single and multiple straight paths. Int. J. Mach. Tools Manuf. 68, 30-39 (2013)

7. Hashish, M.: Milling with abrasive-waterjets: a preliminary investigation. ASME, p. 10 (1987)

8. Fowler, G.: Abrasive water-jet - controlled depth milling titanium alloys, p. 209 (2003)

9. Alberdi, A., Rivero, A., López de Lacalle, L.N., Etxeberria, I., Suárez, A.: Effect of process parameter on the kerf geometry in abrasive water jet milling. Int. J. Adv. Manuf. Technol. 51(5-8), 467-480 (2010)

10. Bui, V.H., Gilles, P., Cohen, G., Rubio, W.: A modeling of elementary passes taking into account the firing angle in abrasive water jet machining of titanium alloy. In: AIP Conference Proceedings, vol. 1960 (2018)

11. Ojmertz, K.M.C.: Abrasive waterjet milling: an experimental investigation (1997)

12. Sultan, T., Gilles, P., Cohen, G., Cenac, F., Rubio, W.: Modeling incision profile in AWJM of Titanium alloys Ti6A14V. Mech. Ind. 17(4), 403 (2016)

13. Bui, V.H., Gilles, P., Sultan, T., Cohen, G., Rubio, W.: A new cutting depth model with rapid calibration in abrasive water jet machining of titanium alloy. Int. J. Adv. Manuf. Technol. 93(5-8), 1499-1512 (2017)

14. Bui, V.H., Gilles, P., Sultan, T., Cohen, G., Rubio, W.: Adaptive speed control for waterjet milling in pocket corners. Int. J. Adv. Manuf. Technol. 103, 77-89 (2019) 
Open Access This chapter is licensed under the terms of the Creative Commons Attribution 4.0 International License (http://creativecommons.org/licenses/by/4.0/), which permits use, sharing, adaptation, distribution and reproduction in any medium or format, as long as you give appropriate credit to the original author(s) and the source, provide a link to the Creative Commons license and indicate if changes were made.

The images or other third party material in this chapter are included in the chapter's Creative Commons license, unless indicated otherwise in a credit line to the material. If material is not included in the chapter's Creative Commons license and your intended use is not permitted by statutory regulation or exceeds the permitted use, you will need to obtain permission directly from the copyright holder.

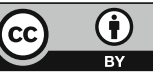

